\title{
Waardenburg Sendromu'nda Tanımlanan Çok Nadir Bir PAX3 Geni Varyantı: C.232G>A (p.Val78Met)
}

\author{
Fatih KURT 國, Mustafa DOĞAN 國, Recep ERÖZ 國3
}

\begin{abstract}
ÖZ
Waardenburg Sendromu(WS); İlk olarak PJ Waardenburg tarafından tanımlanmış, deri, saç, göz veya kohleadaki stria vascularis'te melanositlerin fiziksel yokluğundan kaynaklanan hastalıktır. Poliozis (saçta beyaz perçem), hipopigmente maküller, canlı mavi gözler veya heterokromik iris ve sensörinöral işitme kaybı dahil pigmentasyon anormalliklerinin birlikteliği ile karakterizedir. Bu sendromda altı gen mutasyonu suçlanmaktadır. Bunlar; PAX3 (Paired box 3 transkripsiyon faktörün) geni, MITF (Mikroftalmi ile ilişkili transkripsiyon faktörü) geni, EDN3 (Endotelin 3) geni, EDNRB (Endotelin reseptör tip B) geni, SOX10 (Sry bOX10 transkripsiyon faktörü) geni ve SNAI2 (Snail homolog 2) genleridir. Çok nadir bir hastalıktır, prevelansı 1/42000'dir. Kadın ve erkeklerde eşit oranda görülür. Bu yazıda PAX3 geni ekzon 2'de c.232G>A(p.Val78Met) patojenik varyantı tespit edilerek Waardenburg Sendromu teşhisi konan 2 aylık nadir bir olgu sunulmuştur.
\end{abstract}

Anahtar Kelimeler: Waardenburg Sendromu; PAX3 geni; sensörinöral işitme kaybı.

\section{A very Rare PAX3 Gene Variant Identified in Waardenburg Syndrome: C.232G $>A(p . V a l 78 M e t)$}

\section{ABSTRACT}

Waardenburg Syndrome (WS); it was first defined by PJ Waardenburg. This disease is caused by the physical absence of melanocytes in the stria vascularis of the skin, hair, eyes or cochlea. It is characterized by the association of pigmentation abnormalities including poliosis (white forelock on the hair), hypopigmented macules, bright blue eyes or heterochromic iris and sensorineural hearing loss. Six gene mutations are blamed in this syndrome. These; PAX3 (Paired box 3 transcription factor) gene, MITF (Microphthalmia-associated transcription factor) gene, EDN3 (Endothelin 3) gene, EDNRB (Endothelin receptor type B) gene, SOX10 (Sry bOX10 transcription factor) gene and SNAI2 (Snail homolog 2) are genes. It's a very rare disease, its prevalence is $1 / 42000$. It is seen equally in men and women. In this article, a 2-month-old rare case diagnosed with Waardenburg Syndrome by detecting c.232G> A (p.Val78Met) pathogenic variant in exon 2 of the PAX3 gene is presented.

Keywords: Waardenburg Syndrome; PAX3 gene; sensorineural hearing loss.

\section{GIRIŞ}

Waardenburg Sendromu (WS); İlk olarak Waardenburg tarafından tanımlanmıs, deri, saç, göz veya kohleadaki stria vascularis'te melanositlerin fiziksel yokluğundan kaynaklanan hastalıktır $(1,2)$. Poliozis (saçta beyaz perçem), hipopigmente maküller, canlı mavi gözler veya heterokromik iris ve sensörinöral işitme kaybı dahil pigmentasyon anormalliklerinin birlikteliği ile karakterizedir. Bununla birlikte, distopia kantorum, kas-iskelet sistemi anormallikleri, Hirschsprung hastalığı veya nörolojik kusurlar gibi diğer özellikler hastaların alt gruplarında bulunur ve WS'nin klinik sınıflandırmasında kullanılır (3). Hastalığın temel bulgularına ek olarak distopia kantorum varsa WS Tip I, yoksa WS Tip II olarak adlandırılır. WS Tip 1'e ilaveten üst ekstremite tutulumu, mikrosefali, iskelet anomalileri ve mental retardasyon bulunursa Klein-Waardenburg Sendromu (WS Tip III) olarak adlandırlır. Tip 2 ile birlikte Hirschsprung Hastalığı'nın varlığı ise Shah-Waardenburg Sendromu (WS Tip IV) olarak adlandırılır $(4,5)$. Bu sendromda altı gen mutasyonu suçlanmaktadır. Bunlar; PAX3 (Paired box 3 transkripsiyon faktörün) geni, MITF (Mikroftalmi ile ilişkili transkripsivon faktörü) geni, EDN3 (Endotelin 3) geni, EDNRB (Endotelin reseptör tip B) geni, SOX10 (Sry bOX10

1 Düzce Atatürk Devlet Hastanesi, Çocuk Sağlığı ve Hastalıkları Kliniği, Düzce, Türkiye

2 Malatya Turgut Özal Üniversitesi Eğitim ve Araştırma Hastanesi, Tıbbi Genetik Anabilim Dalı, Malatya, Türkiye

3 Düzce Üniversitesi Tıp Fakültesi, Tıbbi Genetik Anabilim Dalı, Düzce, Türkiye 
transkripsiyon faktörü) geni ve SNAI2 (Snail homolog 2) genleridir (6). Hastalık otozomal dominant geçişli olup, kadın ve erkeklerde benzer oranlarda görülür. Prevalansı 1/42.000'dir ve doğumsal işitme kayıplarının \%1-5'sini WS oluşturur $(7,8)$. Burada atipik göz bulguları ile Tıbbi Genetik Polikliniğine konsulte edilen ve yapılan genetik analiz sonucunda PAX3 geni ekzon 2'de c. $232 \mathrm{G}>\mathrm{A}(\mathrm{p} . \mathrm{Val} 78 \mathrm{Met})$ patojenik varyantı tespit edilen 2 aylık nadir bir olgu sunulmuştur.

\section{OLGU SUNUMU}

2 aylık k1z hasta çocuk sağlığı ve hastalıkları polikliniğinden dismorfik göz bulguları nedeni ile tıbbi genetik polikliniğine konsulte edildi. Hasta 25 yaşında G1P1Y1 anneden 38w3d, 1690 gr ağırlığında, boy $43 \mathrm{~cm}$ olarak $\mathrm{C} / \mathrm{S}$ ile doğmuş. Anne ve baba arasında 3. derece akrabalık mevcuttu. Annenin kronik hastalık öyküsü bulunmayıp, gebelikte diş tedavisi için amoksisilinklavunat ve konjonktivit nedenli tobramisin damla kullanım öyküsü mevcuttu. Hasta yenidoğan döneminde bradikardi nedeni ile yenidoğan yoğun bakım ünitesinde yatmış olup tedavi başlanmamış, üç gün takip edilmiş, takibinde kalp atımları normale gelmesi üzerine taburcu edilmişti. Hastanın başvurusunda aktif şikayeti yoktu. Yapılan fizik muayanede ağırlık $3150 \mathrm{gr}$, boy $49,5 \mathrm{~cm}$, baş çevresi $34 \mathrm{~cm}$ olarak saptandı. Hastanın genel durumu iyi, aktif, hareketli, saç muayenesi doğal, poliozis yok, kulakların yapısı doğal, ağız içi lezyon yok, yarık damak ve yüksek damak yoktu. Gözlerde hipertelorizm, blefarofimozis, distopia kantorum ve heterokromik iris mevcuttu. Sol el parmaklarında hipopigmente maküller, yay kaşlar ve hipertrikozis mevcuttu (Şekil 1a ve 1b). Hastanın fotoğraflarının yazıda kullanılması konusunda aileden onam alınmıştır.

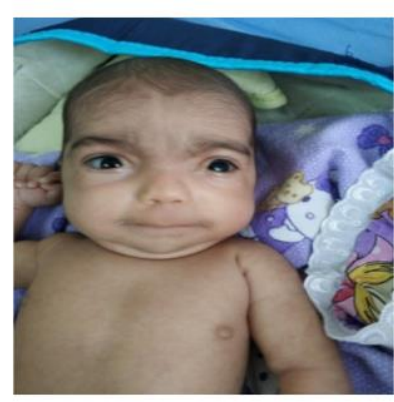

a

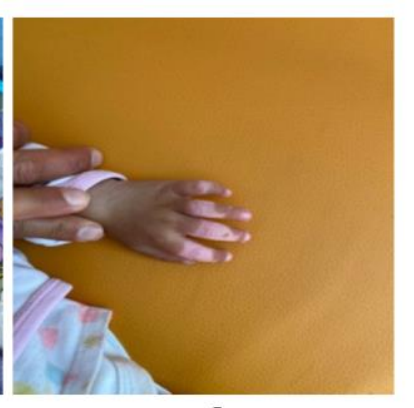

b
Şekil 1. (a) Heterokromik iris, hipertelorizm, blefarofimozis, yay kaşlar, hipertrikoz. (b) Parmaklarda hipopigmente maküller

Kalp sesleri doğal, S1 +, S2 +, ek ses ve üfürüm yoktu. Solunum sesleri ve dış genital muayenesi doğal ve batın rahatt1. Ekstremitelerinde hafif spastisite mevcuttu. Olgunun ilk 48 saatte gayta çıkışı olmuş ve rutin işitme taramasından bilateral geçmişti. Hastanın göz bulguları, hipopigmente makülleri ve hafif spastisitesi nedenli WS düşünülmesi nedeniyle yapılan mutasyon analizinde PAX3 geni ekzon 2'de çok nadir bir c.232G>A (p.Val78Met) varyasyonunu heterozigot taşıdı̆̆1 saptand 1 (Şekil 2).

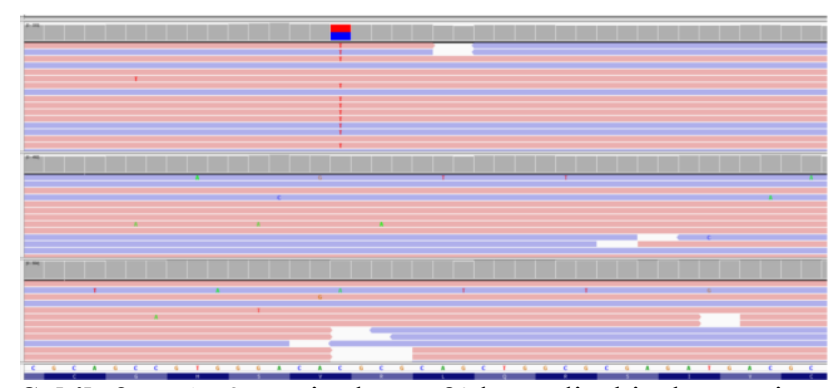

Şekil 2. $\overline{P A X} 3$ geni ekzon 2'de nadir bir heterozigot c. $232 \mathrm{G}>\mathrm{A}(\mathrm{p}$. Val78Met) varyasyonu

\section{TARTIŞMA}

Hollandalı oftalmolog ve genetikçi PJ Waardenburg tarafından 1951 yılında tanımlanan WS deri, saç, göz veya kokleadaki stria vascularis'te melanositlerin fiziksel yokluğundan kaynaklanmaktadır (2). Distopia kantorum, blefarofimozis, çıkık geniş burun kökü, kaşların medial kısmının hipertrikozu, poilozis (beyaz perçem), hipopigmente maküller, canlı mavi gözler veya heterokromik iris ve sensörinöral işitme kaybı dahil pigmentasyon anormalliklerinin birlikteliği ile karakterize otozomal dominant geçişli bir hastalıktır $(1,3,9)$. Kasiskelet sistemi anormallikleri, Hirschsprung hastalığ veya nörolojik kusurlar gibi diğer özellikler hastalığın alt gruplarında bulunur ve WS'nin klinik sınıflandırmasında kullanılır (4). Waardenburg Konsorsiyumu tarafindan önerilen tanı kriterleri Tablo 1'de verilmiştir. Tanı için iki major veya bir major ve iki minör kriter olması yeterlidir (10).

Waardenburg Sendromunun 4 alt tipi vardır. Tip 1; PAX fonksiyonel mutasyonunun ortaya çıkardığı tablodur. Bu alt tipinde bütün tipik semptomlar ve distopia kantorum görülür. Tip 2; MITF (Microphtalmia Associated Transcription Factor) mutasyonuna bağlı ortaya çıkar. Bu tabloda Heterokromik iris ve sensörinöral işitme kaybı görülür ancak distopia kantorum yoktur. Tip 3; Klein Waardenburg Sendromu da denilir. Tip 1'e benzer fakat kas iskelet sistemi anomalileri eşlik eder. Tip 4; Otozomal resesif geçişli tek tiptir. Endothelin 3 geninde, EDNRB(Endothelin reseptör tip B) geninde veya SOX 10 genindeki mutasyonlar sonucu görülür. Waardenburg Sendromuna Hirschsprung Hastalığı eşlik etmesi yönünden önemlidir $(6,11,12)$.

Waardenburg Sendromu ortalama 42.000 doğumda bir, her iki cinste ve tüm ırklarda eşit olarak görülmektedir. Konjenital sağırlı olgularının yaklaşık \%5'ini WS oluşturmaktadır ancak tam sağırlık çok yüksek oranda görülmez. Bu hastalardaki işitme kaybının nedeni spiral gangliyon ve sinirde atrofik değişiklikler ile corti organındaki defektlerdir. Waardenburg Sendromlu hastaların ancak \%17' sinde işitme ileri seviyede etkilenmiştir. WS'de simetrik ya da asimetrik olabilen nörosensoriyel işitme kayb1 seviyesi hafiften ileri dereceye kadar değişkendir. WS Tip I' de olguların \%3575'inde WS Tip II' de ise \%55- 90' inda işitme kaybı vardır $(4,13)$. Bizim olgumuz 2 aylıktır ve tarama amaçlı yapılan işitme testinden her iki kulaktan geçmiştir. Waardenburg Sendromlu hastalarda üç tür iris pigment bozukluğu gözlenebilir; tam, kısmi veya segmental heterokromi şeklindedir. Bu lezyonlar tek taraflı veya iki taraflı olabilir, hatta iki taraflı izohipokromik iris (soluk mavi göz) şeklinde de görülebilir. WS olan bireylerin \% 
21-28'inde kısmi ya da tam iris pigmentasyon bozukluğu gözlenebilir. En yaygın \%47 oranında Tip 2 de görüldüğü bildirilmiştir. $\mathrm{Bu}$ hastalarda fundusta yama tarzında hipopigmentasyon, mottling (beneklenme), albinoid tip değişiklikler görülebileceği bildirilmiştir $(14,15)$. Olgumuzda heterokromik iris, hipertelorizm, blefarofimozis mevcuttu (Şekil 1). Waardenburg Sendromlu hastalarda tipik saç bulgusu olan poliozis \%17-58.4 oranında ve kirpik, kaş ve vücut kıllarında erken yaşta ağarma görülebilmektedir (12). Hastamızda yay kaşlar, hipertrikoz mevcut fakat poliozis saptanmamıştır (Şekil 1a). Ayrıca ciltte hipopigmente ve hiperpigmente alanlarda görülebilir (16). Hastamızın sol el parmaklarında hipopigmente maküller mevcuttu (Şekil 1b). Shah-Waardenburg Sendromu'nda (Tip 4 WS) Hirschsprung Hastalığı görülebilmektedir. Waardenburg Sendromu ve Hirschsprung Hastalığı 1/1000000 altında prevelansa sahip oldukça nadir görülen bir hastalıktır (17). Bizim hastamızın ilk 48 saat içerisinde gayta çıkışı olduğu ve dışkılamasının normal olduğu öğrenildi, bu nedenle Hirschsprung Hastalığı düşünülmedi. Hastanın yapılan FM de ekstremitelerde spastisite saptandi. Özgeçmişinde bradikardi nedenli Yenidoğan Yoğun Bakım Ünitesi'nde yatışının yapıldı̆̆ı, fakat asfiksi, mekanik ventilasyon ihtiyacı öyküsü olmadığı öğrenildi. Tip 3 Waardenburg Sendromu'nda ekstremite tutulumu, iskelet anomalileri olabileceğinden hasta spastisite açısından ve işitme ileri inceleme için çocuk nöroloji bölümüne konsultasyonu planland1 (15).

Waardenburg Sendromu altı farklı gen mutasyonundan kaynaklanmaktadır. Bunlar; PAX3, MITF, EDN3, EDNRB, SOX10 ve SNAI2 genleridir (6). Hastamızın Sanger sekanslama ile yapılan $P A X 3$ geni tüm gen dizi analizinde 2. ekzonda p.Val78Met varyasyonunu heterozigot olarak taşıdığı saptand. Hastanın soygeçmişinde hastalığın özelliklerinin olmaması, anne ve babasinda yapilan genetik analizde mutasyon saptanmaması nedeniyle tespit edilen mutasyon spontan mutasyon olarak kabul edildi. Olguya ait soyağacı Şekil 3 'te verilmiştir.

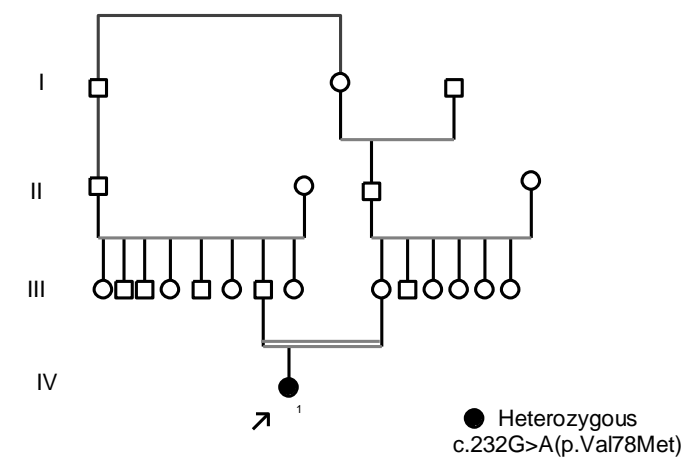

Şekil 3. Hastanın Aile Soyağacı

Literatürde 2016'da aynı lokasyonda muhtemel patojenik bir varyant [NM_181458.4(PAX3):c.232G>T (p.Val78Leu)] Waardenburg tip 1 ile ilişkilendirilmiştir (20).

Bizim vakamızda tespit ettiğimiz varyant aynı lokusta farklı bir aminoasit dönüşümüne yol açan nadir bir varyantt1. Daha önce sadece bir vakada bildirilmiş olan (bu vakada detaylı klinik bilgi paylaşılmamış ancak WS tip 1 olarak belirtilmiştir) çok nadir bir varyanttır (18).
$P A X 3$ genindeki varyantın sıralama görünümü Tablo 2'de verilmiştir. 2015 yılında yayınlanan ACMG kriterlerine göre varyant "patojenik" olarak belirlenmiştir(19). Varyant için patojenite verileri Tablo 2'de gösterilmektedir.

Yazarların Katkıları: Fikir /Kavram: F.K., M.D., R.E.; Tasarım: F.K., M.D., R.E.; Denetleme: F.K., M.D., R.E.; Kaynaklar: F.K., M.D., R.E.; Veri Toplama F.K., M.D., R.E.; Analiz ve Yorum: F.K., M.D., R.E.; Literatür Taraması: F.K., M.D., R.E.; Yazıyı Yazan: F.K., M.D., R.E.; Eleştirel İnceleme: F.K., M.D., R.E.

\section{KAYNAKLAR}

1. Waardenburg PJ. A new syndrome combining developmental anomalies of the eyelids, eyebrows and nose root with pigmentary defects of the iris and head hair and with congenital deafness. Am J Hum Genet. 1951; 3: 195-253.

2. Read AP, Newton VE, Waardenburg Syndrome, J Med Genet. 1997; 34(8): 656-65.

3. Tosun F, Kertmen M, Yetişer S, Satar B, Özkaptan Y. Waardenburg Sendromu: Klinik sınıflama ve üç farklı olgu sunumu. Kulak Burun Boğaz Klinikleri. 2000; 2: 37-40.

4. Kilıçarslan H, Eser İ, Şener HM, Akkuş M. Waardenburg Sendromu: Olgu sunumu. Genel Tip Derg. 2008; 18(4): 173-6.

5. Bondurand N, Dastot-Le Moal F, Stanchina L, Collot N, Baral V, Marlin S, et al. Deletions at the SOX10 gene locus cause Waardenburg Syndrome types 2 and 4. Am J Hum Genet. 2007; 81(6): 1169-85.

6. Pingault V, Ente D, Dastot-Le Moal F, Goossens M, Marlin S, Bondurand N. Review and update of mutations causing Waardenburg Syndrome. Hum Mutat. 2010; 31(4): 391-406.

7. Oysu C, Baserer N, Tinaz M. Audiometric manifestations of Waardenburg's Syndrome. Ear Nose Throat J. 2000; 79: 704-9.

8. Taşkın E, Kılıç M, Aydın M, Ertuğrul S, Denizmen Aygün A. Bir olgu nedeniyle Waardenburg Sendromu. F.Ü.Sağ.Bil.Tıp.Derg. 2004; 18(4): 251-3.

9. Mancini AJ. Waardenburg Syndrome Type II in a Taiwanese woman with a family history of pseudoxanthoma elasticum. Int J Dermatol. 1997; 36(12): 933-5.

10. Konno P, Silm H. Waardenburg Syndrome. J Eur Acad Dermatol Venereol. 2001; 15(4): 330-3.

11. Toki F, Suziki N, Inoue K, Suzuki M, Hirakata K, Nagai $\mathrm{K}$, et al. Intestinal aganglionosis associated with the Waardenburg Syndrome: Report of two cases and review of the literature. Ped Surg Int. 2003; 19(11): 725-8.

12. Dourmishev AL, Dourmishev LA, Schwartz RA, Janniger CK. Waardenburg Syndrome. Int J Dermatol. 1999; 38(9): 656-63.

13. Grundfast KM, Atwood JL, Cuong D. Genetics and molecular biology of deafness. Otolaryngol Clin North Am. 1999; 32(6): 1067-88.

14. Önder Hİ, Tunç M, Yüksel H, Sılan F, Kaya M. Waardenburg Sendromlu hastalarda göz bulguları. Düzce Tıp Derg. 2013; 15(3): 60-3. 
15. Nork TM, Shihab ZM, Young RSL, Price J. Pigment distribution in Waardenburg's Syndrome: A new hypothesis. Graefe's Arch Clin Exp Ophthalmol. 1986; 224(6): 487-92.

16. Krishtul A, Galadari Y. Waardenburg Syndrome: Case report. Int J Dermatol. 2003; 42(8): 651-2.

17. Cui L, Hoi-Man Wong E, Cheng G, Almeida MF, So MT, Sham PC, et al. Genetic analyses of a three generation family segregating hirschsprung disease and 1ris heterochromia, PLoS One. 2013; 8(6): e66631.

18. Tassabehji M, Newton VE, Liu XZ, Donnai D, Krajewska-Walasek M, Murday, et al. The mutational spectrum in Waardenburg Syndrome. Hum Mol Genet. 1995; 4(11): 2131-7.

19. Richards S, Aziz N, Bale S, Bick D, Das S, GastierFoster J, et al. Standards and guidelines for the interpretation of sequence variants: a joint consensus recommendation of the american college of medical genetics and genomics and the association for molecular pathology. Genet Med. 2015; 17(5): 40512.

20. Milunsky J. ncbi.nlm.nih.gov [internet]. Center for Human Genetics, Inc.; Massachusetts United States: Clinvar; 2017 Dec 20 [Updated: 2021 Jan 25; cited : 2021 Feb 3]. Available from: https://www.ncbi.nlm.nih.gov/clinvar/variation/54773 $5 /$. 